\title{
A mixed-methods survey to explore issues with virtual consultations for musculoskeletal care during the COVID-19 pandemic
}

\author{
Anthony W Gilbert ${ }^{1,2 *}$, Gregory Booth ${ }^{1}$, Tony Betts $^{1}$ and Andy Goldberg $3,4,5$
}

\begin{abstract}
Objective: To explore orthopaedic and musculoskeletal clinicians' views and experiences of legal, safety, safeguarding and security issues regarding the use of virtual consultations (VC) during the COVID-19 pandemic. A secondary objective was to suggest ways to overcome these issues.

Methods: A mixed method cross-sectional survey was conducted, seeking the views and experiences of orthopaedic and musculoskeletal medically qualified and Allied Health Professionals in the United Kingdom. Descriptive statistical analysis was employed for quantitative data and a qualitative content analysis undertaken for qualitative data. Findings were presented in accordance with the four key issues.

Results: Two hundred and ninety professionals (206 physiotherapists, 78 medically qualified professionals, 6 'other' therapists) participated in the survey. Of the 290 participants, 260 (90\%) were not using VC prior to the COVID-19 pandemic, 248 respondents (86\%) were unsure whether their professional indemnity insurance covered VC, 136 (47\%) had considered how they would handle an issue of safeguarding whilst the remainder had not, 126 (43\%) had considered what they would do if, during a virtual consultation, a patient suffered an injury (e.g. bang on their head) or a fall (e.g. mechanical or a medical event like syncope) and 158 (54\%) reported they felt the current technological solutions are secure in terms of patient data. Qualitative data provided additional context to support the quantitative findings such as validity of indemnification, accuracy of diagnosis and consent using VC, safeguarding issues; and security and sharing of data. Potential changes to practice have been proposed to address these issues.

Conclusions: VC have been rapidly deployed since the onset of the COVID-19 pandemic often without clear guidance or consensus on many important issues. This study identified legal, safeguarding, safety and security issues. There is an urgent need to address these and develop local and national guidance and frameworks to facilitate ongoing safe virtual orthopaedic practice beyond the COVID-19 pandemic.
\end{abstract}

\footnotetext{
* Correspondence: anthony.gilbert@nhs.net

${ }^{1}$ Therapies Department, Royal National Orthopaedic Hospital, Stanmore, UK

${ }^{2}$ School of Health Sciences, University of Southampton, Southampton, UK

Full list of author information is available at the end of the article
}

C The Author(s). 2021 Open Access This article is licensed under a Creative Commons Attribution 4.0 International License, which permits use, sharing, adaptation, distribution and reproduction in any medium or format, as long as you give appropriate credit to the original author(s) and the source, provide a link to the Creative Commons licence, and indicate if changes were made. The images or other third party material in this article are included in the article's Creative Commons licence, unless indicated otherwise in a credit line to the material. If material is not included in the article's Creative Commons licence and your intended use is not permitted by statutory regulation or exceeds the permitted use, you will need to obtain permission directly from the copyright holder. To view a copy of this licence, visit http://creativecommons.org/licenses/by/4.0/. The Creative Commons Public Domain Dedication waiver (http://creativecommons.org/publicdomain/zero/1.0/) applies to the data made available in this article, unless otherwise stated in a credit line to the data. 


\section{Introduction}

The outbreak of the 2019 novel coronavirus (COVID 19) was first reported in Wuhan, China and reached the United Kingdom on the 31st January 2020. The COVID19 virus spreads primarily through droplets of saliva or discharge from the nose when an infected person coughs or sneezes. Social distancing measures have been established; the UK public were placed on 'lockdown' from the 23rd March 2020 [1] to avoid transmission of the disease.

Around a fifth of primary care consultations are for musculoskeletal problems [2, 3]. Consultations for patients with musculoskeletal problems may include a physical examination [4] [5], radiographs [4], exercises [6], self management [7], and manual therapy [8] (such as manipulation [9] or mobilisations [10]). Patients may have expectations of a thorough physical examination [11], individualised exercises, manual handling and 'hands on' treatment [12]. Virtual orthopaedic surgical [13-15] and rehabilitation [16-22] consultations have been found to be a viable alternative to face-to-face consultations. The outbreak of COVID-19 has led to a huge upsurge in the interest and importance of virtual consultations (VC) in practice [23-25] with patients being forced into undergoing VC. Much of the COVID-19 research around $\mathrm{VC}$ has focused on the process of rapid role out [23], its capability [26] and future direction [27, 28]. Some the research since COVID-19 has posed important questions around the issues of whether it is suitable for all [29], accessible for all [30] and how to overcome challenges to prevent medicolegal issues from occurring [31].

To our knowledge, no research has yet investigated issues encountered by orthopaedic and musculoskeletal clinicians using VC since the onset of COVID-19. The objective of the study was to explore orthopaedic and musculoskeletal clinicians' views of potential legal, safety, safeguarding and security issues regarding the use of $\mathrm{VC}$ during the COVID-19 pandemic. A secondary objective was to suggest ways to overcome these issues.

\section{Methods}

Design

Mixed-method cross sectional survey.

\section{Ethics}

This study was registered with the local Research and Innovation Centre. The Health Research Authority granted approvals on the 3rd August 2020 (IRAS ID: 244738).

\section{Questionnaire development}

A questionnaire was developed by the study's authors to explore issues encountered due to the use of $\mathrm{VC}$ during the COVID-19 pandemic. An initial consultation between the authors (AWG = research physiotherapist, $\mathrm{GB}$ and $\mathrm{TB}=$ specialist physiotherapists; $\mathrm{AG}=$ Consultant Orthopaedic Surgeon) identified four broad topics of importance. These topics were identified as important based on anecdotal experience of VC during the pandemic. The questionnaire was designed to quantitatively assess the presence of these phenomenon and qualitatively explore respondents' views on these topics. The four topic areas of interest and definitions are shown below:

(i) Legal issues - which we define as those relating to indemnification between the patient and the clinician potentially resulting from their $\mathrm{VC}$ interaction.

(ii) Safeguarding issues - which we define as the process of protecting individuals for whom we care.

(iii) Safety issues- which we define as risks to the patient and clinician resulting from the VC interaction.

(iv) Security issues - which we define as risks resulting from data loss or data breaches because of the VC interaction.

Open textboxes were included to encourage participants to provide qualitative data. The questionnaire was piloted with five physiotherapists and five orthopaedic surgeons prior to dissemination of the final instrument to ensure that it was accessible to the target audience. No material changes were suggested to the questionnaire. The final questionnaire can be seen in the supplementary material (supplementary material 1).

\section{Participants and recruitment}

The questionnaire was circulated via email and social media on the 4th August 2020 using the online platform 'Survey Monkey'. The survey was disseminated across professional networks in the United Kingdom including the British Orthopaedic Association, the Association of Trauma and Orthopaedic Chartered Physiotherapists and the Digital Informatics Physiotherapy Group. The email encouraged colleagues to disseminate the survey widely. Participants were required to determine their eligibility prior to participating. Participants were eligible to participate providing they met the inclusion criteria shown in Table 1 . This study sought to recruit at least 200 participants. This was a pragmatic decision that was made to ensure meaningful data analysis.

\section{Data analysis}

Descriptive statistics were used to present quantitative data; inferential statistics were not used as this study sought only to identify the range of issues rather than make inferences from these data. A qualitative content analysis [32] was employed to identify empirical 
Table 1 Inclusion criteria

\begin{tabular}{ll}
\hline Inclusion Criteria & Exclusion Criteria \\
\hline - Medically qualified professionals. & • No experience of conducting VC. \\
OR & • Unable to provide informed consent. \\
- Practicing Allied Health Professional (eg physiotherapist, podiatrist). & \\
AND & \\
- Working in a trauma / orthopaedics / musculoskeletal setting. & - Experience of conducting VC.
\end{tabular}

regularities within the data relating to these 4 themes outlined and defined above. We then mapped these to the coding framework which included the four issues of interest and 'other issue'. This took the following forms:

i) A coding framework was developed consisting of the four issues outlined above and 'other issue'

ii) Qualitative data were exported into an excel spreadsheet.

iii) Data were assigned a code by one author (AWG) to depict the type of issue represented within the data. The codes that were used related to the four issues of interest (legal issue, safeguarding issue, safety issue, security issue) or 'other issue' for those that did not fit within the definitions offered above.

iv) Codes were reviewed by a second author (GB). A third author (TB) was available to resolve any disagreements.

v) Data were organised into the coding framework based on the assigned code.

vi) A description of the type of content was presented for each issue.

\section{Reporting}

This study was reported in accordance with the STROBE checklist for cross sectional studies and can be seen in the supplementary material (supplementary material 2).

\section{Results \\ Responses}

Three hundred and thirty-seven participants accessed the survey, 67 responses were empty and were therefore excluded, 310 responses were completed with a further 20 excluded as they were not using VC. Two hundred and ninety responses were included for analysis. Qualitative responses were coded relating to the four issues of interest. Of the 219 qualitative responses, 43 were coded as legal issues, 76 were coded as safeguarding issues, 79 were coded as safety issues, 10 were coded as security issues and 11 were coded as multiple / other. No disagreements between the first two authors arose in the allocation of coding. Quantitative data are shown in Table 2. Examples of qualitative data are shown in Table 3.

\section{VC usage and demographics of participants}

Of the 290 participants, 260 (90\%) were not using VC prior to the COVID-19 pandemic, 206 participants (71\%) were physiotherapists, 78 participants (27\%) were medically qualified professionals, 6 were 'other' Allied Health Professionals (2\%).

Table 2 Summary of quantitative results

\begin{tabular}{|c|c|c|c|}
\hline Question & Yes & No & Unsure \\
\hline $\begin{array}{l}\text { Are you using virtual consultations with patients? } \\
(n=298)\end{array}$ & $\begin{array}{l}279 \\
(94 \%)\end{array}$ & $\begin{array}{l}19 \\
(6 \%)\end{array}$ & $\begin{array}{l}0 \\
(0 \%)\end{array}$ \\
\hline $\begin{array}{l}\text { Were you using virtual consultations before COVID-19 } \\
(n=298)\end{array}$ & $\begin{array}{l}30 \\
(10 \%)\end{array}$ & $\begin{array}{l}268 \\
(90 \%)\end{array}$ & $\begin{array}{l}0 \\
(0 \%)\end{array}$ \\
\hline $\begin{array}{l}\text { Do you feel the current technological solutions are secure in terms of patient data? } \\
(n=296)\end{array}$ & $\begin{array}{l}159 \\
(54 \%)\end{array}$ & $\begin{array}{l}24 \\
(8 \%)\end{array}$ & $\begin{array}{l}113 \\
(38 \%)\end{array}$ \\
\hline $\begin{array}{l}\text { Have you considered how, in a virtual consultation, you would handle an issue of safeguarding? } \\
(n=298)\end{array}$ & $\begin{array}{l}138 \\
(46 \%)\end{array}$ & $\begin{array}{l}38 \\
(13 \%)\end{array}$ & $\begin{array}{l}122 \\
(41 \%)\end{array}$ \\
\hline $\begin{array}{l}\text { Have you considered what you would do if, during a virtual consultation, a patient suffered an injury } \\
\text { (eg bang on their head) or a fall (even if a medical event like syncope)? } \\
(n=298)\end{array}$ & $\begin{array}{l}130 \\
(44 \%)\end{array}$ & $\begin{array}{l}123 \\
(41 \%)\end{array}$ & $\begin{array}{l}45 \\
(15 \%)\end{array}$ \\
\hline $\begin{array}{l}\text { Does your professional indemnity cover you for any injuries sustained by patients during a virtual } \\
\text { consultation? } \\
(n=298)\end{array}$ & $\begin{array}{l}44 \\
(15 \%)\end{array}$ & $\begin{array}{l}4 \\
(1 \%)\end{array}$ & $\begin{array}{l}250 \\
(84 \%)\end{array}$ \\
\hline $\begin{array}{l}\text { Have you encountered any other legal issues surrounding the use of virtual consultations since COVID-19? } \\
(n=298)\end{array}$ & $\begin{array}{l}258 \\
(87 \%)\end{array}$ & $\begin{array}{l}40 \\
(13 \%)\end{array}$ & $\begin{array}{l}0 \\
(0 \%)\end{array}$ \\
\hline
\end{tabular}

$\mathrm{n}=$ number of respondents 


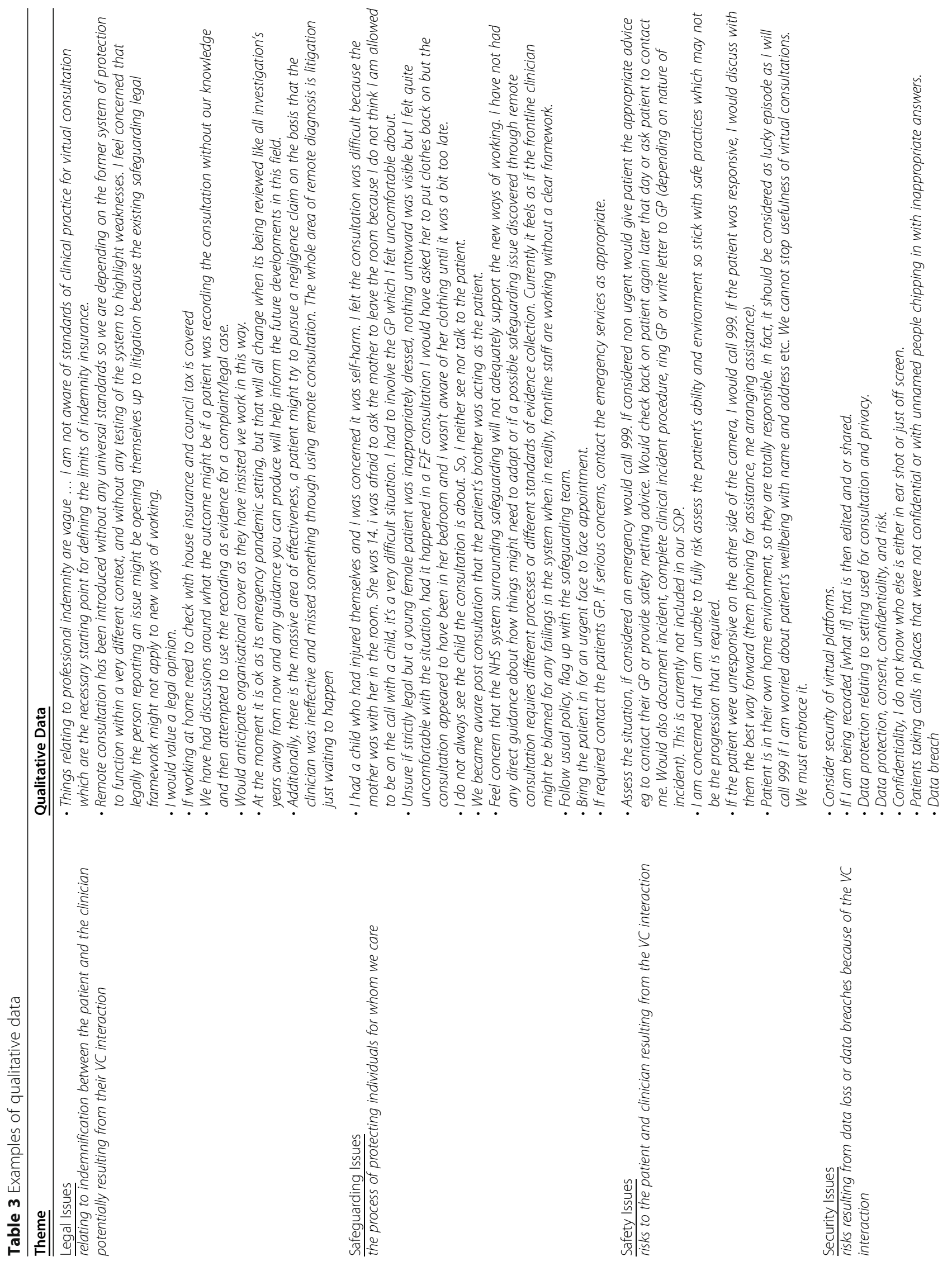




\section{Legal issues}

Two hundred and forty-eight respondents (86\%) were unsure whether their professional indemnity insurance covered VC. Just 42 respondents (14\%) reported knowing that their indemnity covered them for injuries sustained during a VC. Some respondents assumed that this would be covered by their NHS Trust or that the indemnity would stretch to $\mathrm{VC}$ as they were operating within the scope of their public role. Others stated that since insurance providers allowed clinicians to undertake VC during the COVID-19 lockdown' they assumed that these may be covered moving forwards, but they were uncertain. One respondent questioned whether their home insurance covered them for conducting clinical consultations from home.

Participants reported the challenges of virtual diagnosis that would normally warrant a physical examination as well as the difficulties in delivering effective interventions which often require a hands-on approach. One respondent raised concerns about the effectiveness of a digital intervention:

'Additionally, there is the massive area of effectiveness, a patient might try to pursue a negligence claim on the basis that the clinician was ineffective and missed something through using remote consultation. The whole area of remote diagnosis is litigation just waiting to happen".

$\mathrm{VC}$ revealed potential issues of setting with examples including patients driving during a consultation, taking a call in a noisy and crowded environment and whilst cleaning a fishpond.

\section{Safeguarding issues}

One hundred and thirty-six participants (47\%) had considered how they would handle an issue of safeguarding whilst the remainder had not. Over half (56\%) of participants had not considered or were unsure of safeguarding issues. Seventy-one participants commented, and strategies to handle safeguarding issues were suggested (see Table 3).

General themes emerged such that certain clinicians felt discouraged from using $\mathrm{VC}$ due to concerns over safeguarding such as a lack of visual clues on the area not within the view of the camera. One clinician reported being concerned with the potential of a patient having self-harmed and the challenges of being unable to conduct a formal assessment. One respondent reported a family member of the patient visibly naked in the background. One male clinician reported feeling uncomfortable at not being able to offer a chaperone to a female patient, whilst another reported feeling uncomfortable and vulnerable undertaking a $\mathrm{VC}$ with an inappropriately dressed young female patient.

It was noted by several participants that it was important to confirm the location of the patient at the outset of the consultation and to ask sensitising questions to identify issues of safeguarding. Some clinicians stated they would refuse to use $\mathrm{VC}$ for new patients purely due to the potential safeguarding risks.

Confidentiality was a frequent concern. It was difficult for clinicians to control who was present in the patient's room and some reported situations where family members were answering on behalf of the patient and providing inappropriate answers. An example was given where a relative was pretending to be a patient. Several respondents reported concerns about being recorded.

\section{Safety issues}

One hundred and twenty-six participants (43\%) had considered what they would do if, during a virtual consultation, a patient suffered an injury (e.g. bang on their head) or a fall (e.g. mechanical or a medical event like syncope). More than half (57\%) however, had not considered how they would respond if such a situation were to occur. Some participants reported that they had developed standard operating procedures to guide clinicians in what to do if such an event were to occur. A concern was raised about the logistics of managing students and the challenges of providing supervision to support their safe practice. Most respondents stated that they would call the emergency services or the patient's general practitioner. It was deemed important to ascertain if the patient was alone at the start of the session and confirm the next of kin's contact details.

\section{Security issues}

Of the 290 participants, 158 (54\%) reported they felt the current technological solutions are secure in terms of patient data. Twenty-three (8\%) did not feel that the current technological solution is secure and 109 (38\%) were not sure. Issues raised included security by the host platform (of data loss and third party recording); the recording of consultations by patients and subsequent sharing; and compliance with data laws such as General Data Protection Requirements (GDPR).

\section{Other issues}

In addition to the four specific issues we investigated, we gained insights into a small number of other issues that were reported amongst the participant responses. These can be seen in Table 3 .

\section{Discussion}

Our study has identified a range of issues experienced by clinicians in a musculoskeletal setting, $90 \%$ of whom had 
not been using VC prior to the onset of the COVID-19 pandemic.

The issues have been categorised into legal (86\%) such as ability to make an accurate diagnosis and validity of indemnification; safeguarding issues, such as the lacking of visual clues outside of the camera view; safety issues, such as how to deal with a patient falling in their home during a consultation; and security issues, such as data loss or breach of data laws.

\section{Legal issues}

To indemnify is to 'to pay somebody an amount of money because of the damage or loss that they have suffered' [33]. All doctors and physiotherapists must have appropriate indemnity as a condition of their registration with the General Medical Council [34] and Health and Care Professions Council [35] respectively. Despite being registered with indemnity providers, $86 \%$ of respondents were unclear whether their indemnifiers provided cover for VC. It is the responsibility of the healthcare professional to ensure they have adequate coverage both for patient and public liability.

Another concern was raised in relation to professional versus public liability. Public liability insurance is usually taken by a hospital or clinic to protect individuals who come to harm in or on the insured property. However, when it comes to $\mathrm{VC}$, the patient is usually in their own property which may not be covered.

Accuracy of diagnosis and adequacy of consent using $\mathrm{VC}$ themes were raised. Delays in diagnosis features as the most common cause for litigation in hip fracture claims [36]. Wade and colleagues [37] identified VC as a potential cause for reduced diagnostic accuracy. This might lead to increased liability due to lower quality consultations. In a review of successful litigation against English Health Trusts in the treatment of adults with orthopaedic pathology [38] seventy-eight cases of "poor consent process" resulted in successful litigation claims. The use of VC during the consenting process may impact on the discussion of treatment options and risks.

\section{Safeguarding issues}

Self-cutting has previously been identified as the most common form of deliberate self-harm representing $45 \%$ of self-harm cases [39]. A large proportion of respondents had not considered safeguarding issues (53\%) and participants comments identifies concerns in this area due to a combination of technology restraints, lack of external clues, and privacy. VC can adversely affect the flow of the conversation [40] which may impact a clinicians attempt to undertake a thorough subjective assessment. Poor internet connection is commonly reported [41] and interferes with transmission of information [42].
Lack of confidentiality may manifest through a lack of physical privacy if the patient's environment is not conducive to having a quiet space for their appointment [37]. Cranen and colleagues [43] found that patients suffering with chronic pain valued telerehabilitation but hesitated to use it as an autonomous treatment. Patients expressed concern at feeling alienated through telerehabilitation and service providers may feel inclined to offer virtual groups to facilitate fellow sufferer contact which may also lead to confidentiality issues.

\section{Safety issues}

Protocols for managing the fallen patient exist within a healthcare setting [44]. Virtual rehabilitation may include strengthening and balance exercises designed to challenge patients' proprioception, particularly those susceptible to falls. Less than half of respondents in our study had considered safety issues such as falls and how to manage them in $\mathrm{VC}$ and guidance published in response to COVID-19 does not appear to consider this either [26].

A study of telephone consultations in primary care found that clinicians expressed strong concerns about safety being compromised as a result of lack of formal and informal examination [45]. Guidance to ensure the safety of patients and clinicians in delivering $\mathrm{VC}$ is needed.

\section{Security issues}

Concerns about data security are not new [37] and were raised by participants in our study. In the UK, NHSX is a joint unit bringing together teams from the Department of Health and Social Care and NHS England and NHS Improvement to drive the digital transformation of care. NHSX released guidance for healthcare professionals during the pandemic [46] which included relaxation of governance restrictions to optimise virtual care. The Chartered Society of Physiotherapy (CSP) released guidance for physiotherapists around rapid implementation of remote consultations [47] which included (if no other alternative) using own devices and commercial apps where there is no practical alternative and the benefits outweigh the risks [46].

Healthcare data breaches account for three-quarters of overall data breaches in the last 5 years [48]. Of these, hacking and malicious attacks have affected over 145 million individuals between 2015 and 2019. A number of data breaches occurred in the first half of 2020 [49], with access of personal data featuring in all ten highlighted cases. A survey of 43 senior plastic surgeons [50] elicited their views on the future of virtual consultations in plastic surgery; $38 \%$ of respondents were not aware of encryption and $48 \%$ were unaware of GDPR compliance. As the number of remote consultation platforms grow, it 
is essential that patients and clinicians are aware of their potential security issues and that policies and procedures reflect increased risks [51].

In addition, the recording of $\mathrm{VC}$ either by the clinician or the patient and subsequent sharing, for example on social media [52], is an area of controversy which needs further research. A recent study [53] provided an overview of legal considerations for both patients and clinicians that focuses around consent, sharing of recordings, ownership of recordings and data security and storage. Eleven states in the USA require all party consent to legally record a conversation [52]. In contrast, in the UK, patients and relatives can record a consultation without the clinicians consent, because the information being recorded is personal to them and is exempt from the Data Protection Act (DPA) and General Data Protection Regulation (GDPR) [54].

\section{Strengths and limitations}

This study must be considered in light of its limitations. The questionnaire was developed by the authors and as a result the phenomenon of interest investigated may have been subject to bias. A wider range of questions may have identified additional issues of interest. Although no disagreements arose in coding of qualitative data, this may be due to the general definitions decided upon at the outset of the study. Recruitment of a more diverse range of participants, a higher volume of participants and engagement with pre-existing theory or frameworks may have led to more generalisable results. Reporting bias may be present if respondents with negative views favoured participation. As with all surveys, recall bias may occur. That said, this pragmatic study is believed to be the largest survey of musculoskeletal clinicians to date to investigate issues of VC due to COVID19 and it offers a potential starting point for discussion across the orthopaedic and musculoskeletal community.
A strength of this study is that it was developed and shared during the pandemic; the questions were developed by clinicians experienced in developing and enacting virtual consultation pathways due to COVID-19. The closed nature of questions within the questionnaire provided an indication of the prevalence of issues across our sample and the open questions provided useful qualitative data and insights that can be used to guide development and refinement of future policy to address issues identified. This study provides a potential starting point for future research to expand upon.

\section{Implications for future practice and clinical research}

Our study identified several potential issues in clinical practice. Table 4 offers some potential suggestions for practice:

The COVID-19 pandemic has changed the virtual healthcare landscape. Pragmatic evaluation of virtual pathways would assist in the identification of additional issues not alerted in this work. Thorough evaluation of patient and clinician experience, in addition to service outcomes, is essential to determine effectiveness and acceptability.

\section{Conclusion}

$\mathrm{VC}$ have been rapidly deployed since the onset of the COVID-19 pandemic often without clear guidance or consensus on many important issues. This research has identified legal, safeguarding, safety and security issues relating to $\mathrm{VC}$ for musculoskeletal care during the COVID-19 pandemic. During the first wave of the pandemic, emergency rules applied, and many participants within this study had not considered many of the issues explored in this study. Careful consideration must go to whether research published prior to COVID-19 serves as an appropriate basis for post COVID-19 policy. Future policy should be developed following a thorough

Table 4 Potential suggestions for practice

\begin{tabular}{|c|c|}
\hline Issue & Suggestions \\
\hline Legal & $\begin{array}{l}\text { (i) Provide information for patients about what a VC can and cannot do. } \\
\text { (ii) Establish a 'code of conduct' that provides patients with information about what is acceptable. } \\
\text { (iii) Ensure adequate indemnity insurance (including Cybercover) is in place for the individual and } \\
\text { organisation and that policy exclusions are transparent. }\end{array}$ \\
\hline Safeguarding & $\begin{array}{l}\text { (i) Establish a robust process of patient identification. } \\
\text { (ii) Ensure patient has access to a chaperone. } \\
\text { (iii) Ensure safeguarding policies at institution consider issues of VC. }\end{array}$ \\
\hline Safety & $\begin{array}{l}\text { (i) Provide guidance for patients on establishing a safe environment for virtual consultations. } \\
\text { (ii) Conduct risk assessment of physical environment patient-side. } \\
\text { (iii) Establish protocols for clinical assessments. } \\
\text { (iv) Establish procedures for managing patient incidents during virtual consultations. }\end{array}$ \\
\hline Security & $\begin{array}{l}\text { (i) Establish clear guidance on the security of the various technology platforms available. } \\
\text { (ii) Determine whether data is encrypted } \\
\text { (iii) Establish that appropriate approvals are in place by providers and indemnifiers. } \\
\text { (iv) Complete Data Protection Impact Assessment prior to roll out, considering relevant data protection } \\
\text { guidance and policy. }\end{array}$ \\
\hline
\end{tabular}


appraisal of the safety and effectiveness of $\mathrm{VC}$ employed since COVID-19. As we move towards the next waves of the pandemic, there is an urgent need to address these issues and plug the gaps. This study has highlighted how some clinicians across musculoskeletal and orthopaedic care may not have an awareness of these concerns. Focusing on potential legal, safeguarding, safety and security issues and proactively addressing them may facilitate ongoing safe virtual orthopaedic practice beyond the COVID-19 pandemic.

\section{Supplementary Information}

The online version contains supplementary material available at https://doi. org/10.1186/s12891-021-04113-y.

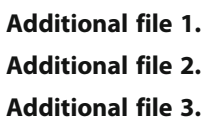

\section{Acknowledgements}

The authors are grateful to Iva Hauptmannova and colleagues at the Royal National Orthopaedic Hospital Research and Innovation Centre and

Therapies Department for their support.

\section{Patient and public involvement}

It was not possible to involve patients or the public in the design, or conduct, or reporting, or dissemination plans of our research.

\section{Authors' contributions}

AWG and AG conceived the project. All authors designed the survey, AWG completed data analysis with assistance from TB, GB and AG. AWG drafted the manuscript. All authors edited and critically revised the manuscript. All authors have read and approved the manuscript.

\section{Funding}

This study was unfunded. Anthony Gilbert, Clinical Doctoral Research Fellow (ICA-CDRF-2017-03-025) is funded by Health Education England and the National Institute for Health Research (NIHR). Gregory Booth is an ICA Predoctoral Clinical Academic Fellow supported by Health Education England and the National Institute for Health Research. The views expressed in this publication are those of the author(s) and not necessarily those of the National Institute for Health Research or the Department of Health and Social Care.

\section{Availability of data and materials}

Data from this study are available upon reasonable request to the corresponding author.

\section{Declarations}

\section{Ethics approval and consent to participate}

This study was registered with the local Research and Innovation Centre. Approvals were received from the Health Research Authority on the 3rd August 2020 (IRAS ID: 244738). All methods were carried out in accordance with relevant guidelines and regulations. Informed consent was obtained from all participants.

\section{Consent for publication}

Not applicable.

\section{Competing interests}

The Authors declare that there is no conflict of interest.

\section{Author details}

${ }^{1}$ Therapies Department, Royal National Orthopaedic Hospital, Stanmore, UK

${ }^{2}$ School of Health Sciences, University of Southampton, Southampton, UK.
${ }^{3}$ Institute of Orthopaedics and Musculoskeletal Sciences, University College London, London, UK. ${ }^{4}$ Trauma and Orthopaedics Department, Wellington Hospital, London, UK. ${ }^{5}$ MSK Lab, Imperial College London, London, UK.

Received: 30 November 2020 Accepted: 18 February 2021

Published online: 05 March 2021

\section{References}

1. England PH. Number of coronovirus (COVID-19) cases and risk in the UK 2020 [Available from: https://www.gov.uk/guidance/coronavirus-covid-19information-for-the-public accessed 29 Mar 2020.

2. Goff I, Wise E, Coady D, et al. Musculoskeletal training: are GP trainees exposed to the right case mix for independent practice? Clin Rheumatol. 2016;35(2):507-11. https://doi.org/10.1007/s10067-014-2767-z.

3. Keavy R. The prevalence of musculoskeletal presentations in general practice: an epidemiological study. Br J Gen Pract. 2020;70(suppl 1) doi: https://doi.org/10.3399/bjgp20X711497

4. Fehring TK, Valadie AL. Knee instability after total knee arthroplasty. Clin Orthop Relat Res. 1994;299:157-62.

5. Tsukayama DT, Goldberg VM, Kyle R. Diagnosis and management of infection after total knee arthroplasty. J Bone Joint Surg Am. 2003;85A(Suppl 1):S75-80

6. Jordan KM, Arden NK, Doherty M, et al. EULAR recommendations 2003: an evidence based approach to the management of knee osteoarthritis: report of a task force of the standing Committee for International Clinical Studies Including Therapeutic Trials (ESCISIT). Ann Rheum Dis. 2003;62(12):1145-55. https://doi.org/10.1136/ard.2003.011742

7. Zhang W, Moskowitz RW, Nuki G, et al. OARSI recommendations for the management of hip and knee osteoarthritis, part II: OARSI evidence-based, expert consensus guidelines. Osteoarthritis \& Cartilage. 2008;16(2):137-62.

8. Bialosky JE, Bishop MD, Price DD, et al. The mechanisms of manual therapy in the treatment of musculoskeletal pain: a comprehensive model. Man Ther. 2009;14(5):531-8. https://doi.org/10.1016/j.math.2008.09.001.

9. Coronado RA, Gay CW, Bialosky JE, et al. Changes in pain sensitivity following spinal manipulation: a systematic review and meta-analysis. J Electromyogr Kinesiol. 2012;22(5):752-67. https://doi.org/10.1016/j.jelekin.2 011.12.013.

10. Ho C-YC, Sole G, Munn J. The effectiveness of manual therapy in the management of musculoskeletal disorders of the shoulder: a systematic review. Man Ther. 2009;14(5):463-74.

11. Calner T, Isaksson G, Michaelson P. "I know what I want but I'm not sure how to get it"-expectations of physiotherapy treatment of persons with persistent pain. Physiotherapy Theory And Practice. 2017;33(3):198-205. https://doi.org/10.1080/09593985.2017.1283000.

12. Potter M, Gordon S, Hamer P. The physiotherapy experience in private practice: the patients' perspective. Australian Journal of Physiotherapy. 2003; 49(3):195-202. https://doi.org/10.1016/S0004-9514(14)60239-7.

13. Buvik A, Bugge $E$, Knutsen $G$, et al. Patient reported outcomes with remote orthopaedic consultations by telemedicine: a randomised controlled trial. J Telemed Telecare. 2019;25(8):451-9. https://doi.org/10.1177/1357633X18783 921.

14. Buvik A, Knutsen G, Småbrekke A, et al. Quality of care for remote orthopaedic consultations using telemedicine: a randomised controlled trial. BMC Health Serv Res. 2016;16:1-11. https://doi.org/10.1186/s12913-016-171 7-7.

15. Kingsbury SR, Dube B, Thomas CM, et al. Is a questionnaire and radiographbased follow-up model for patients with primary hip and knee arthroplasty a viable alternative to traditional regular outpatient follow-up clinic? 2016. p. 201-8.

16. Salisbury C, Montgomery A, Hollinghurst S, et al. Effectiveness of PhysioDirect telephone assessment and advice services for patients with musculoskeletal problems: pragmatic randomised controlled trial. $\mathrm{BMJ}: \mathrm{Br}$ Med J. 2013;346(7893):14. https://doi.org/10.1136/bmj.f43.

17. O'Brien KM, Hodder RK, Wiggers J, et al. Effectiveness of telephone-based interventions for managing osteoarthritis and spinal pain: a systematic review and meta-analysis, 2018

18. O'Brien KM, Wiggers J, Williams A, et al. Telephone-based weight loss support for patients with knee osteoarthritis: a pragmatic randomised controlled trial. Osteoarthr Cartil. 2018;26(4):485-94.

19. Bennell KL, Nelligan R, Dobson F, et al. Effectiveness of an internet-delivered exercise and pain-coping skills training intervention for persons with 
chronic knee pain: a randomized trial. Ann Intern Med. 2017;166(7):453-62 https://doi.org/10.7326/M16-1714.

20. Cottrell MA, Galea OA, O'Leary SP, et al. Real-time telerehabilitation for the treatment of musculoskeletal conditions is effective and comparable to standard practice: a systematic review and meta-analysis. Clin Rehabil. 2017; 31(5):625-38. https://doi.org/10.1177/0269215516645148.

21. Shukla H, Nair SR, Thakker D. Role of telerehabilitation in patients following total knee arthroplasty: evidence from a systematic literature review and meta-analysis. J Telemed Telecare. 2017;23(2):339-46.

22. Owusu-Akyaw KA, Hutyra CA, Evanson RJ, et al. Concurrent validity of a patient selfadministered examination and a clinical examination for femoroacetabular impingement syndrome. BMJ Open Sport Exerc Med. 2019;5:1.

23. Gilbert A, Billany J, Adam R, et al. Rapid implementation of virtual clinics due to COVID-19: Report and early evaluation of a Quality Improvement initiative. BMJ Open Qual. 2020; Accepted ahead of print.

24. Greenhalgh T, Koh GCH, Car J. Covid-19: a remote assessment in primary care. BMJ (Clinical research ed). 2020;368:m1182. https://doi.org/10.1136/bmj. m1182.

25. Greenhalgh T, Wherton J, Shaw S, et al. Video consultations for covid-19. BMJ (Clinical research ed). 2020;368:m998. https://doi.org/10.1136/bmj.m998.

26. Tanaka MJ, Oh LS, Martin SD, et al. Telemedicine in the era of COVID-19: the virtual Orthopaedic examination. J Bone Joint Surg (Am Vol). 2020;102(12): e57. https://doi.org/10.2106/JBJS.20.00609.

27. Satin $A M$, Lieberman $\mathbb{H}$. The virtual spine examination: telemedicine in the era of COVID-19 and beyond; 2020.

28. Tack CT, Grodon J, Shorthouse F, et al. "Physio anywhere": digitallyenhanced outpatient care as a legacy of coronavirus 2020. Physiotherapy. https://doi.org/10.1016/.jphysio.2020.07.004.

29. Kilvert $A$, Wilmot $E G$, Davies $M$, et al. Virtual consultations: are we missing anything? Practical Diabetes. 2020;37(4):143-6. https://doi.org/10.1002/pdi.22 88.

30. Foundation GT. Digital Nation UK 2020 Online2020 [Available from: https:// www.goodthingsfoundation.org/sites/default/files/research-publications/ digital-nation-2020.pdf accessed 20 Nov 2020

31. Malik RA, Sadler P. Remote consultations; what you need to know. Middle East J Family Med. 2020;18(10):103-6. https://doi.org/10.5742/MEWFM.2020 93880.

32. Schreier M, Stamann C, Janssen M, et al. Qualitative Content Analysis: Conceptualizations and Challenges in Research Practice--Introduction to the FQS Special Issue "Qualitative Content Analysis I". Forum: Qualitative Soc Res. 2019:20(3):1-26. https://doi.org/10.17169/fqs-20.3.3393.

33. Dictionaries OLs. Indemnify Online2020 [Available from: https://www. oxfordlearnersdictionaries.com/definition/english/indemnify accessed 17 Nov 2020.

34. Council GM. Insurance indemnity and medico-legal support Online2020 [Available from: https://www.gmc-uk.org/registration-and-licensing/mana ging-your-registration/information-for-doctors-on-the-register/insuranceindemnity-and-medico-legal-support accessed 17 Nov 2020.

35. HCPC. Professional Indemnity Online2018 [cited 2020 17th November]. Available from: https://www.hcpc-uk.org/registration/your-registration/legalguidelines/professional-indemnity/.

36. Fanous R, Sabharwal S, Altaie A, et al. Hip fracture litigation: A 10-year review of NHS Litigation Authority data and the effect of national guidelines; 2017. p. 17-21.

37. Wade VA, Eliott JA, Hiller JE. A qualitative study of ethical, medico-legal and clinical governance matters in Australian telehealth services. J Telemed Telecare. 2012;18(2):109-14.

38. Atrey $A$, Gupte $C M$, Corbett SA. Review of successful litigation against english health trusts in the treatment of adults with orthopaedic pathology: clinical governance lessons learned. J Bone Joint Surg Am. 2010;92(18):e36. https://doi.org/10.2106/JBJS.J.00277.

39. Gillies D, Christou MA, Dixon AC, et al. Prevalence and characteristics of selfharm in adolescents: meta-analyses of community-based studies 1990-2015. J Am Acad Child Adolesc Psychiatry. 2018;57(10):733-41. https://doi.org/10.1 016/j.jaac.2018.06.018.

40. Shaw SE, Seuren LM, Wherton J, et al. Video consultations between patients and clinicians in diabetes, Cancer, and heart failure services: linguistic ethnographic study of video-mediated interaction. J Med Internet Res. 2020; 22(5):e18378. https://doi.org/10.2196/18378.
41. Agnieszka I, Helen A, Celia Janine B, et al. Internet videoconferencing for patient-clinician consultations in long-term conditions: a review of reviews and applications in line with guidelines and recommendations. Digital Health. 2019;5. https://doi.org/10.1177/2055207619845831.

42. Galway N, Stewart G, Maskery J, et al. Fifteen-minute consultation: a practical approach to remote consultations for paediatric patients during the COVID-19 pandemic. Arch Dis Childhood Educ Pract ed. 2020. https:/ doi.org/10.1136/archdischild-2020-320000.

43. Cranen $\mathrm{K}$, Drossaert CHC, Brinkman ES, et al. An exploration of chronic pain patients' perceptions of home telerehabilitation services. Health Expect. 2012;15(4):339-50. https://doi.org/10.1111/j.1369-7625.2011.00668.x.

44. NICE. Falls in older people: assessing risk and prevention Online2013 [Available from: https://www.nice.org.uk/guidance/cg161/resources/falls-inolder-people-assessing-risk-and-prevention-pdf-35109686728645 accessed 17 Nov 2020.

45. McKinstry $B$, Watson $P$, Pinnock $H$, et al. Telephone consulting in primary care: a triangulated qualitative study of patients and providers. Br J Gen Pract. 2009;59(563):433-40. https://doi.org/10.3399/bjgp09X420941.

46. NHSX. Covid-19 Information Governance advice for health and care professionals 2020 [Available from: https://www.nhsx.nhs.uk/key-informa tion-and-tools/information-governance-guidance/health-care-professionals accessed 29 Mar 20202020.

47. CSP. COVID-19: guide for rapid implementation of remote consultations Online: Chartered Society of Physiotherapy; 2020 [Available from: https:// www.csp.org.uk/system/files/publication_files/Remote\%20consultations\%2 0top\%20tips\%20v9.pdf accessed 19 Nov 2020.

48. Seh AH, Zarour M, Alenezi M, et al. Healthcare Data Breaches: Insights and Implications, 2020

49. Davis J. UPDATE: the 10 biggest healthcare data breaches of 2020, So Far Online: Health IT Security; 2020 [cited 2020 17th November 2020]. Available from: https://healthitsecurity.com/news/the-10-biggest-healthcare-data-brea ches-of-2020-so-far.

50. Sinha $\mathrm{V}$, Malik $\mathrm{M}$, Nugent $\mathrm{N}$, et al. The role of virtual consultations in plastic surgery during COVID-19 lockdown, 2020.

51. "My data just goes everywhere:" User mental models of the internet and implications for privacy and security; 2019 2019 / 01 / 01 /. USENIX Association.

52. Ferguson BD, Angelos P. Ethical and legal considerations of patients audio recording, videotaping, and broadcasting physician encounters. JAMA surgery. 2020. https://doi.org/10.1001/jamasurg.2020.2968.

53. Prictor M, Johnston C, Hyatt A. Overt and covert recordings of health care consultations in Australia: some legal considerations. Med J Aust. 2020. https://doi.org/10.5694/mja2.50838.

54. Collins J, White P. Question time Online: Chartered Society of Physiotherapy; 2020 [Available from: https://www.csp.org.uk/frontline/article/questiontime-3 accessed 19 Nov 2020.

\section{Publisher's Note}

Springer Nature remains neutral with regard to jurisdictional claims in published maps and institutional affiliations.

Ready to submit your research? Choose BMC and benefit from:

- fast, convenient online submission

- thorough peer review by experienced researchers in your field

- rapid publication on acceptance

- support for research data, including large and complex data types

- gold Open Access which fosters wider collaboration and increased citations

- maximum visibility for your research: over $100 \mathrm{M}$ website views per year

At $\mathrm{BMC}$, research is always in progress.

Learn more biomedcentral.com/submission 